\title{
Introduction
}

Moments of Happiness was a bestseller in Russia. But would it translate into other languages and other contexts? Think of this book as more like a card game, or a prompt for spontaneous theater with your friends, or, of course, a great gift book. Think of it as a game which many different players (of all ages, incidentally) can play. The goal, of course, is to derive some happiness (who doesn't need it?) along the way, but there will be other benefits as well. This introduction describes a few of them.

As cultural stereotypes go, "Russians" and "happy" do not usually go together. Of course, we know that the capacity for happiness is a universal human trait, so, naturally, Russians can be happy just like anyone else, but still ... when Russian culture expresses itself in a way that takes our breath away in the West, it always seems to be on another note: deep, dark, soul-searching, covered in frost, prone to extremes, and so forth. It seems almost heretical to translate a book from Russian that is about happiness. But it's about time.

It turns out that in Russia, as everywhere else, joy can be found in all the usual places (family, friends, accomplishments, food, music, under a starry sky, etc.); and yet, as anthropologists will tell us, different cultures have different patterns of display: what is out in the streets in one society may be confined to the inner courtyards of another, and vice versa. When radio host Alex Dubas simply asked his listeners to call in and share a moment of happiness, right now, while you are stuck in traffic on the way home, it seems that his native audience surprised even themselves. Stories poured in, spontaneously, including the listener who emailed:

Happiness—is hearing about someone else's happiness. I never thought I could cry on a Monday at 4:30 in the afternoon. From happiness.

Who is Alex Dubas? In the original version of Moments of Happiness, he inserted two moments of his own. Following his own rules, Dubas recalled his "moment of happiness" in the present tense, as if he were reliving it now: 
The end of August, 2015. Deauville, Normandy. Noon. I'm sitting on small hill, working on my laptop. The screen blocks my view of La Manche, sailboats, and the city of Le Havre. I'm editing this book. Every so often I tear my eyes away from the screen and look into the distance. A deer just ran by. The scent of late summer flowers and grass. At sunset we'll go horseback riding along the shore. What happiness-to read these stories of other people's happiness, only to get distracted by noticing my own!

In the other "moment" the author allowed himself (in chapter four), we see him howling, literally howling like a wolf, at the moon. His public persona is closer to the moon-howler: in person, he is a celebrity, a performer, a man of great appetites, someone who has ceaselessly moved from one kind of creative-entertainment venture to another.

Dubas was born in 1971 in the Soviet city Kuibyshev (which returned to its prerevolutionary name Samara in 1991). When he was in ninth grade, the family moved to Riga, the capital of Latvia (at the time still part of the USSR). He served in the navy for a year as a diver, then transferred to Lviv (Ukraine) to serve as a military journalist. Dubas has been a Latvian citizen since 1991, and lives and works in Moscow-when he is not traveling. Over the past two decades, his professional passions have included hosting a television series in which he took viewers to "the most interesting corners of the world" in search of cultural, natural, and culinary wonders; hosting shows for Silver Rain, a hip radio station that targets younger, wealthier Russians in over one hundred cities; and performing live on stage in a variety of genres. His theatrical restaging of this book, Kvartirnik [A get-together at my apartment], is discussed below, as well as at the end of this introduction in the note on emotional and ethnographic responses.

You know from the preface that Dubas's Moments of Happiness project was born out of a flash of inspiration in 2015 when, as a radio host, he desperately needed to improvise on air for an hour after a planned celebrity guest failed to materialize. To this day, people who happened to be listening to that radio show describe it as an extraordinary event, in which something genuine and unexpected happened to about one million people at the same time. In a society that is used to trauma, that hour of spontaneous storytelling felt like a collective reckoning - only this time with something deeply positive, even happy! Dubas set out to recapture and extend the magic in various ways: soliciting more stories on social media and 
the radio, gathering them into a book, and performing them on stage as Get-Together at My Apartment.

The staging worked: reading the stories out loud brings each one back to life, but channeled through someone else's voice. An actor's voice, or it could be your voice. Try it - the experience of "putting yourself in someone else's shoes" in the moment when the person in those shoes feels happy. When you realize "That could have been me!" in the process of channeling someone else's story, the effect is genuinely startling. These "moments of happiness" happened to people thousands of miles away, whose culture, language, and surroundings are so different! And yet so many of them strike us in a way that is utterly familiar, and somehow surprising for that reason. The young woman who caught the look of undisguised approval and pride on the face of her mother, who was usually so critical (chapter three). The fun of arriving in a big city to visit a friend who lives downtown - and opening the hatch to his attic apartment only to discover that there's a party on the roof! (chapter one) The rush of completing a difficult, even dangerous, hike through the mountains; or realizing that in an ordinary moment you have the power to acknowledge your own happiness. As one of these stories puts it, "Happiness is discovering a book or a film that seems ... as if it's about me" (chapter six).

It's like a card game. You flip open the book and read: "A moment later she brings in fresh, homemade buns filled with black currant jam, still warm from the oven; she kneaded that dough three times last night. With a glass of milk" (chapter one). How ordinary, almost a cliché. Certainly it's not all about the black currant jam; in someone else's world, it could be chocolate chips or dulce de leche. At the same time, the narrator tells us, she is watching a Disney cartoon for the very first time; prior to 1989, Soviet TV did not broadcast Western fare. In that moment, her childhood horizon has suddenly expanded beyond belief-the novelty of American-style animation and character was profound-but, at the same time, there's the warm taste of Grandma's baking. How often do we associate a mind-blowing experience (of new music, a new perspective, a new friendship) with the food or drink we had at the same time? In fact, what if the simple, separate components of each "moment" described in this book were inscribed on a deck of cards? It would be possible to deal an enormous variety of hands, each of which, as in real life, probably contain the match-ups that spark our happiness. With a bit of practice, attention, and luck, we get better at noticing the possibilities we hold in our hands. 
This book works in the opposite way of the sorts of posts on social media which have now been labeled a mental health hazard. I know that you know that I know that being exposed to endless images of other people's happiness on the internet makes us feel inadequately blissful—and less happy as a result. Instead, this book collects moments of happiness that remind you of your own. Or perhaps some of these stories remind you of an older relative or friend. Regift them.

In Dubas's original version of Moments of Happiness, the stories are listed from 1/ to 947/, without any guiding principle of organization. Nothing connects one story with the ones that follow it or precede it, other than the fact that our perceptions of happiness are immeasurably diverse and unpredictable. This edition abandons the numbering, but applies a light hand of organization. We hope that readers will enjoy figuring out for themselves what themes shine through in the six chapters, and we leave it to our readers to decide how they want to title- or re-title-the chapters.

Finally, we have included photographs by the contemporary St. Petersburg photographer Alexander Petrosyan. Like many of the "moments" in the book, Petrosyan's images capture happiness tinged with something else-an awareness of chance and impermanence, the tension between fleeting moments and lasting memories.

\section{ABOUT THE PHOTOGRAPHER}

Alexander Petrosyan is a professional photographer based in St. Petersburg, Russia. He has won multiple awards for his original and outstanding work. We are honored to showcase a few of his Petersburg images in this edition of Dubas's book. Petrosyan's artistic lens captures moments of life. He is fascinated by the instant-which can contain contradictory elements of beauty and the grotesque, the mystical and the ordinary. Yet in each "moment of life" that Petrosyan records for us, we discover one of the many tonalities of happiness, ranging from the contemplative and worshipful to the silly and boisterous. For more of Petrosyan's photographs, visit his website at http://aleksandrpetrosyan.com/en/. 


\section{ABOUT THE NAMES}

Many people sent in their "moments of happiness" anonymously. Where people signed their names, we have included their first names in this edition. In the case of well-known actors, journalists, and musicians that Dubas interviewed for this book, we include the full name and a reference note.

\section{ON EMOTIONAL (VERSUS) ETHNOGRAPHIC READINGS}

The legendary Russian linguist Roman Jakobson (émigré and professor at Harvard) thought about what the study of poetry and prose can tell us about different types of aphasia (loss of speech, memory disorders in language). To understand why patients lose their ability to "find their words" in different ways, he described the difference between what literary scholars call metaphoric and metonymic thinking. We can do the same in order to think about why the impact of sharing these "moments of happiness" out loud, as part of a social or theatrical performance, is different than reading them silently, to yourself.

As Jakobson pointed out, when we use metaphors the crucial element of meaning is created along what he called the "axis of similarity." If you say your love is like a rose, we are jolted into seeing the unexpected similarity between those two things, and the power of communication is a function of what meaning is created when two things-love and roseare brought together in similarity.

A metonym, on the other hand, creates meaning along the "axis of contiguity." The White House is not a metaphor for the president: it's kind of a spatial extension of his body. So, "The White House announced today ..." or "The sail [standing for "boat"] disappeared on the horizon ..." are figures of speech that work because we recognize that one element stands for another.

When these moments of happiness are voiced in front of an audience, it's the metaphorical impulse that matters. You think "That could have been me!" or "That's so similar to my experience, something I've felt in a different place, with different props, but that story is mine, except in a parallel universe." This experience "along the axis of similarity" is mostly emotional.

By contrast, when we read these moments silently, one after another, our minds start to run along the "axis of contiguity." We find ourselves thinking about how the reading of one 
moment, by virtue of their proximity, affects my reading of the one that happens to come next. That proximity brings out contrasts one would not have seen otherwise. Or perhaps the relationship between one story and the next invokes other patterns in the mind. This experience "along the axis of contiguity" seems ethnographic. Taken together, as Dubas notes in his preface, these stories can be understood as a record of what ordinary Russians were actually thinking and feeling during a period of historical change-from end of the old Soviet Union to the post-Soviet era. In this book, that change is mostly recorded as an unprecedented shift towards acknowledging one's right to-and delight in—all kinds of private, personal, idiosyncratic, individual moments of happiness. The state is nowhere to be seen.

\section{FOR TEACHERS AND DISCUSSION GROUPS}

"Either way, you're holding this book in your hands. . .." Now what? This collection of moments lends itself to a variety of playful (or instructive) exercises in which students or participants can select various categories through which to read the moments. You might ask readers to rate the moments according to a scale of happiness-from "Highly Individualistic" to "Acknowledging the Power of the Collective Good," for example. Alternatively, you could categorize the moments in terms of happiness that bursts out of newness and discovery to the happiness of returning home, and everything in between. One might ask readers to invent their own system for classifying the tonalities of happiness they find in these stories-from bittersweet to giddy, for instance. What do we call the kind of happiness that flares briefly within a dark story?

As Alex Dubas says in the preface, this is not a scientific manual or a self-help book about happiness. This is a book that we hope readers will make their own, for the sake of their own and others' happiness. 